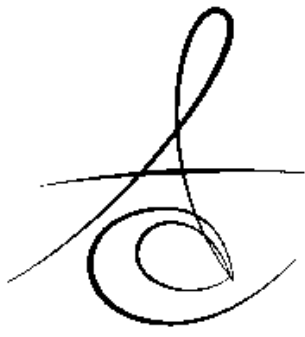

Makale Kodu/Article code:1986

Makale Gönderilme tarihi: 28.11.2014

Kabul Tarihi:15.12.2014

\section{ATİPİK Dİş AĞRISI}

\section{ATYPICAL ODONTALGIA}

Dr. Neslihan TINASTEPE*

\section{ÖZET}

Atipik diş ağrısı, klinik ve radyolojik olarak patolojik bir bulgu olmaksızın diş, dişeti veya dişsiz boşlukta görülen kronik bir ağrıdır. Ağrı, genellikle künt ve süreklidir. Ağrı, büyük oranda dişhekimlerinin klinikte uyguladıkları rutin tedaviler sonrası ortaya çıkar . Bu nedenle dişhekimlerinin bu durum ile karşılaşma intimalleri diğer hekimlere oranla daha fazladır. Etiyolojisi, teşhis ve tedavisi henüz tam olarak anlaşılamamıştır. Bu makalede dişhekimlerinin tüm dental tedavi yaklaşımlarına rağmen, geçmeyen bir ağrı ile karşılaştıklarında daha fazla invaziv yöntemlerden kaçınmalarının önemini vurgulamak amacıyla hazırlanmıştır.

Anahtar Kelimeler: Diş ağrısı, Trigeminal nöralji, Kronik ağrı Giriş

Atipik diş ağrısı, dişhekimlerinin nadir de olsa karşılaşabileceği kronik ağrılardan birisidir. Hastalar herhangi bir klinik ve radyolojik bulgu olmadan diş ya da diş boşluğunda ağrı şikayeti ile dişhekimlerine başvurabilirler. Atipik diş ağrısında ağrı çoğunlukla şiddetli ve devamlı (en az 6 ay ) dır. ${ }^{1}$ Ağrının başlangıcı hemen hemen her zaman restoratif, endodontik tedaviler , küretaj gibi işlemlerden sonra ortaya çımaktadır. $^{2}$ İlk olarak Mclean ve Horton ${ }^{3}$ tarafından 67 yıl önce tanımlansa da , terminolojik, patofizyolojik , teşhis ve tedavi metodları açısından henüz bir fikir birliğine varılamamıştır. ${ }^{4}$ Atipik yüz ağrısı, kronik devamlı dentoalveolar ağrı bozukluğu ${ }^{5}$, devamlı idiyopatik yüz ağrısı $^{6}$, fantom diş ağrısı ${ }^{2}$ bu rahatsızlık için literatürde kullanılan terimler arasındadır. Dişhekimliği'nde kullanılan klasik metodlar var olan ağrıyı azaltmak yerine daha da kötüleştirir. Bu tür hastalar ağrılarını dindirmek için hekimden hekime dolaşırlar. 2003 yııında yapılan bir araştırmada, ağız yüz ağrısı ileardarda başvuran hastaların \%30'una daha önce kanal tedavisi, çekim, apikal rezeksiyon,temporomandibular eklem cerrahisi, ortognatik cerrahi gibi geri dönüşümsüz maksilofasyal cerrahiişlemler uygulandığı bildirilmiştir. ${ }^{7}$

$\mathrm{Bu}$ derlemede atipik diş ağrısının terminolojik gelişimi, patofizyolojisi, klinik semptomları ve tedavi yaklaşımları değerlendirilmiştir.

\section{Etiyoloji}

Tüm hastalıklarda olduğu gibi kronik ağrının tedavisinin de etkin bir şekilde yapılabilmesi için altta yatan ağrı mekanizmalarının iyi bilinmesi gereklidir. Atipik diş ağrısı için son 50 yılda değişik patofizyolojik mekanizmalar öne sürülmüştür. Bunları başlıca 3 grup altında sınıflandırabiliriz:

*Yeditepe Üniversitesi Diş Hekimliği Fakültesi, Protetik Diş Tedavisi AD 


\section{Psikojenik teori}

Bazı araşıırmacılar atipik diş ağrısının primer olarak psikojenik olduğunu düşünürken diğerleri ise psikolojik problemlerin ağrı kaynakı olarak ikincil şekilde ortaya çıktığını savunmuşlardı. ${ }^{8-13}$

Psikojenik ağrıda mental, emosyonel ve davranışsal faktörler ağrının başlangıcl, ilerlemesi ve artmasında etkilidir. ${ }^{14}$ Yapılan araştırmalarda atipik diş ağrısı, depresyon, somatoform ağrı bozuklukları, anksiyete, hipokondriak psikoz, içedönüklük arasında ilişki bulunduğu rapor edilmiştir. ${ }^{4}$ Graff- Radford ve ark ${ }^{11} 1993^{\prime}$ te atipik diş ağrısı ve başağrısı hastalarını depres- yon açısından incelemişler ve aralarında bir farklılık bulamamışlardır. Brooke ve Merskey ise 1994'te depresyonun tek başına atipik diş ağrısı sebebi olmadığını ancak ağrıya katkıda bulunacağını öne sürmüştür. ${ }^{15}$ Son yıllarda yapılan bir araştırmada ise atipik diş ağrısı hastalarının sağlıklı kontrol grubuna oranla daha fazla depresyon skorları gösterdikleri rapor edilmiştir. ${ }^{16}$ Sonuçta hangisinin önce yeraldığından bağımsız olarak atipik diş ağrısı ve depresyonun yakın ilişkide bulunduğu açıktır.

\section{Vasküler ağrı teorisi}

Rees ve Harris 1979 'da atipik diş ağrısı hastalarının \% 30'unda migren bulunduğunu düşünerek, atipik diş ağrısınında vasküler ağrı olarak değerlendirilmesi gerektiğini öne sürmüşlerdir. ${ }^{17}$ Son yıllardaki literatürlerde migren ve atipik diş ağrısı ilişkisinin çok fazla olmadığı görülmüş ve bu teori bilimsel olarak desteklenmemiştir. ${ }^{16,18}$

\section{Nöropatik ağrı teorisi}

Yapılan bir araştırmada atipik diş ağrısına sahip kişilerin \% 83'ünün ağrılarının başlama sebebi olarak yapılandiş tedavisiya da cerrahi tedavileri gösterdikleri rapor edilmiştir. ${ }^{19}$ Kanal tedavisi, diş çekimi, apikal rezeksiyon, ortognatik cerrahi, lokal anestezi, zigomatiko-orbital kırıklar primer aferent trigeminal sinir liflerinde deaferentasyon yaratabilmektedir. Bu nedenle atipik diş ağrısının bir nöropatik ağrı olduğu öne sürülmüştür. ${ }^{2,4,16,20}$

Deaferentasyon sonucu periferik ve santral sinir sistemi organizasyon ve faaliyetlerinde değişiklikler olabilmektedir. Sonuç olarak kronik ağrılar ve beraberinde parestezi, dizestezi gibi bulgularda

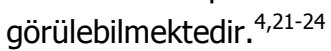

\section{Görülme Sıklığı}

Atipik diş ağrısının çok nadir olduğu düşünülse de yapılan epidemiyolojik çalışmalarda atipik diş ağrısının görülme sıklığı \%2.1 olarak rapor edilmiştir. ${ }^{25}$ Endodontik tedavi gören hastaların ise \%3-6 'sında atipik diş ağrısı görülmektedir. ${ }^{26,27}$

Atipik diş ağrısı kadınlarda erkeklere göre daha fazla görülmektedir ve vakaların \% 80-90'ı kadındır. Tüm yaşlarda görülebilmesine rağmen çocuklarda görülmemektedir. Genellikle 40 yaş ortalarında görülür. $1,8,28$

Üst çenede alt çeneye göre daha fazla oranda (8:2) ve daha çok molar bölgesinde görülmektedir. ${ }^{29,-}$ ${ }^{31}$ List ve arkadaşları 46 atipik diş ağrısı hastasından $\% 56$ 'sının üst çenede ağıı hissettiğini rapor etmişlerdir. ${ }^{32}$

\section{Teşhis Kriterleri}

Atipik diş ağrısı için uluslararası kabul edilen bir teşhis kriteri henüz bulunmamaktadır. Uluslararası Başağrısı Birliği (IHS)'nin Başağrıları, Kranial nöraljiler ve Yüz Ağrıları İçin Sınıflama ve Teşhis Kriterleri'ne göre atipik diş ağrısı devamlı idiyopatik yüz ağrılarının bir alt grubu olarak atipik yüz ağrısı ile birlikte bulunur. Atipik yüz ağrısı, kranial nöraljilerin özelliğini taşımayan ve diğer ağrı bozukluklarına uymayan ağrılar olarak tanımlanmaktadır. (Tablo 1) Bunun yanı sıra IHS atipik diş ağrısını diş ya da diş boşluğundaki devamlı ağrı olarak tanımlamışıı. ${ }^{33}$

Tablo 1. IHS Başağrıları, kranial nöraljiler ve yüz ağrıları sıniflandırmasi ${ }^{33}$

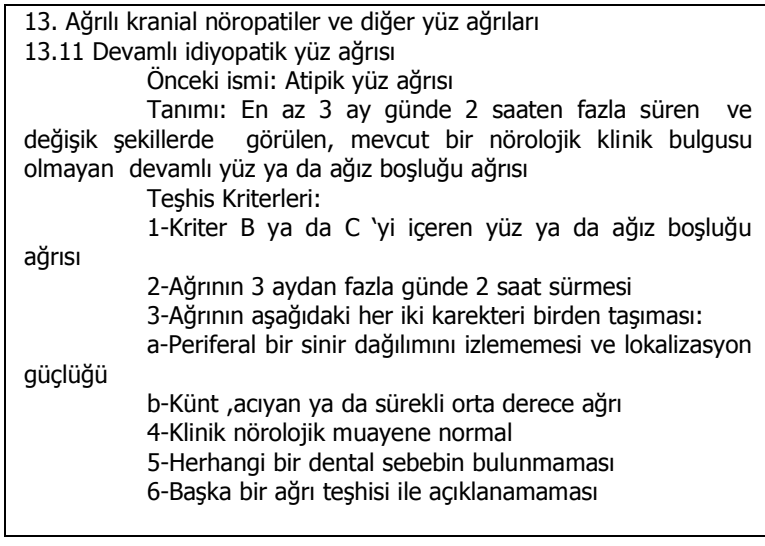

\section{Bulgu ve Belirtileri}

Atipik diş ağrısının en önemli bazen tek belirtisi ağrıdır. Genellikle ağrı devamlı, kendiliğinden ve künttür. ${ }^{1,2,34}$ Bir dişte, dişsiz boşlukta ve bazen tüm alt ya da üst çenede görülebilir. ${ }^{1,35,37-39}$ Ağrı yanan, zonklayan ve keskin olarakta görülebilir. ${ }^{39}$ Ağrı uykuyu 
bölmez ancak uyanınca tekrar başlar. ${ }^{1,2}$ Migren ve küme baş ağrıları atipik diş ağıısına eşlik edebilir. . $^{34,40-42}$ Hiperestezij ${ }^{38}$,alodinya, ${ }^{1,43}$ sıcaklık artması görülebilir ve perküsyon, palpasyon da ağrı şiddetlenebilir. ${ }^{2,35,44}$ Genellikle lokal bir patoloji bulunamaz.

Lokal anestezinin etkisi ağrının mekanizmasına göre çeşitlilik gösterir. Genellikle ağrıyı tam olarak geçirmesede hafifletir. ${ }^{4}$

\section{Ayırıcı Tanı}

Kronik yüz ağrısı olan bir hastaya atipik diş ağrısı koymak için birçok rahatsızlığı ekarte etmek gerekir. Pulpal dişağrısı, trigeminal nevralji, temporomandibular eklem bozuklukları, myofasyal ağrı, pretrigeminal nöralji, sinüzit, göz ve kulak problemleri, çatlak diş sendromu, migrenli nöralji, temporal arterit, kranial nöraljiler, akut herpes zoster, postherpetik nöralji, geniculate nöralji, temporomandibular eklem artriti ayıııcı tanıda düşünülmesi gereken rahatsızlıklardandır. ${ }^{4}$

Pulpa ağrısı ile atipik diş ağrısını ayırt etmek için aşağıda atipik diş ağrısında bulunup pulpa ağrısında bulunmayan 5 özellik sıralanmıştır. (1) Lokal belirgin bir patoloji olmaksızın devamlı diş ağrısı, (2) Sıcak, soğuk ve diş üzerine baskı ağrıyı etkilemez.(3) Ağrı aylar boyunca aynı kalırken, diş ağrısında giderek kötüleşme ya da azalma eğilimindedir. (4) Dental tedaviler başarısızıkla sonuçlanır. (5) Lokal anesteziye cevap değişkendir. ${ }^{36,45}$

Graff-Radford ve ark. yaptıkları araştırmada atipik diş ağrısı bulunan hastalarda ağrıı bölgede ağrısız karşı tarafa göre termografik farklılık bulurken diş ağrısı bulunan hastalarda bu farkllığa rastlamamışlardır. ${ }^{46}$

Kesin bir dental-pulpal bir patoloji olmadan devamlı diş ağrısının diğer bir alternatif açıklaması da çatlak diş sendromudur. Çatlak diş, elektrik ve soğuk testi gibi vitalite testlerine pozitif cevap verecektir. Dişin bir mikroskopla incelenmesi bu alternatifin ortadan kalkmasına yardımcı olacaktır. ${ }^{47}$

Atipik diş ağrısının ayıııı tanısında düşünülmesi gereken diğer bir patolojide trigeminal nöraljidir. İki rahatsızlığın gösterdiği klinik ve epidemiyolojik farklııklar aşağıdaki gibidir: ${ }^{2,28,43,48}$

(1)Ağrı trigeminal sinirin bir ya da daha fazla dalının inerve alanla sınırlı proksismal, tek taraflı, keskin, ani elektriksel, saplanan, tekrarlayıcı tarzdadır. Atipik diş ağrısı ise künt ve devamlıdır. (2) Trigeminal nöraljinin görülme yaşı 40 'tır, 50 ve 60'ı yıllar ise en sık rastlandığı yaşlardır. Atipik diş ağrısı 40 yaş ortalarında ve kadınlarda en sık görülür.(3) Trigeminal nöraljide tetik noktaları dokunma ile ağrıya neden olur.

Ayrıca, atipik diş ağrısı, genellikle dişe uygulanan travmatik bir olay (kanal tedavisi, diş çekimi) sonrasında ortaya çıkar. ${ }^{4}$

Miyofasyal ağrı ve temporomandibular bozuklarda görülen ağrılarda atipik diş ağrısı ile karıştıılabilir. Bu rahatsızlıklardaki ağrılar kulak önü, temporal bölgeyüz ,boyun, omuz bölgelerinde gözlenir, sadece diş bölgesinde nadiren görülür. Çene hareketlerinde genellikle ağrı artar. Miyofasyal ağrılarda tetik noktaları kendiliğinden ya da palpasyonla ağrıya neden olur. ${ }^{4,43,49}$

Pretrigeminal nöralji trigeminal nöralji ortaya çıkmadan günler ya da yıllar önce görülen bir klinik tablodur. ${ }^{50}$ Pretrigeminal nöralji atipik diş ağrısına benzer klinik belirtiler verir. Ağrı yanan, zonklayan ve/veya künt bir karaktere sahiptir. Dişte belirgin bir patolojiye rastlanmazken, genellikle bir diş tedavisi sonrasında ortaya çıkar. ${ }^{4}$

Göz, kulak, sinüs rahatsılıkları gibi diğer ayırt edilmesi gereken rahatsızlara başka semptomların eşlik ettiğinin bilinmesi ayırıı tanıyı kolaylaştıracaktır. ${ }^{4}$

\section{Tedavisi}

Atipik diş ağrısı için uluslararası bir tedavi yöntemi bulunmamakla birlikte çeşitli yöntemler kullanılmaktadır. Bu yöntemlere geçmeden önce atipik bir ağrının beyinde yer alan birçok yapıdan kaynaklanabileceğini bilmek ve organik rahatsızlıkları ekarte etmenin ne kadar önemli olduğunu hatırlatmak gerekir.Patofizyolojisi ve etiyolojisi bilinen tüm çene yüz bölgesi ağrıları açısından incelendikten sonra atipik diş ağrısı tanısı konulabilir. Hastaların çoğu atipik diş ağrısı tanısını kabul etmekte zorlanmakta, hekimin yetersiz olduğunu düşünmekte ve ağrısına çözüm olacak başka hekim arayışına girerek bir klinikten diğerine gitmektedir. Bu doğru tanı arayışı sırasında hasta birçok dental ve cerrahi tedaviye maruz kalmakta ve daha da kötüleşmektedir.

Atipik diş ağrısına diğer fiziksel (myofasyal ağrı, başağrısı) ve psikolojik rahatsızıklarda (depresyon, somatizasyon) çoğunlukla eşlik etmektedir ve tedavisini komplike hale getirmektedir. ${ }^{4}$

Atipik diş ağrısının tedavisinde ilk akla gelen ilaç trisiklik antidepresanlardır (TCA). Birçok literatürde tek başına ya da fenotiazinlerle kullanımlarında iyi sonuç alındığı bildirilmiştir. ${ }^{18,35,51,52}$ 
TCA'ların psikolojik etkilerinden çok analjezik etkilerinin bu sonuçlarda etkili olduğu ve fenatiazinlerinde bu etkiyi arttırdığı düşünülmektedir. ${ }^{45}$ TCA 'ların analjezik etkilerinin temelinde seratonin ve norad- renalin geri alınımının inhibisyonu yer almaktadır.. ${ }^{16}$ TCA'lar içerisinde en sık amitriptilin bu rahatsızlık için günde $25 \mathrm{mg}$ başlangıç dozu ile 100 mg'a kadar kullanılmaktadır. ${ }^{26,28,35,36,39,45,52-56}$

İmipramin ${ }^{35,39,55}$, nortriptirin ${ }^{35}$ ve dotipen ${ }^{17}$ kullanılan diğer TCA' lardandır. Trisiklik antidepresanların yan etkileri bu ilaçların kullanımlarını sınırlandırmaktadır. Ağız kuruluğu, kilo kaybı, kabızlık, glokom, göz tansiyonu bu ilaçların yan etkilerindendir. Fenotiazinler sinir sistemi üzerinde kalıcı etki yaratarak distonyaya neden olabileceklerinden çok dikkatli kullanımalıdırlar. ${ }^{4}$

Gabapentin $^{48}$, pregabalin ${ }^{16}$ klonezepam ${ }^{38,48,54}$, a- ve $\beta$-blokers ${ }^{38}$, aspirin ${ }^{28}$, ,kokain ${ }^{48}$, MAO inhibitörleri ${ }^{10,17}$ de özellikle antidepresanların tolere edemeyeceği durumlarda kullanılmaktadır. Opioid narkotik analjezikler atipik diş ağrısında orta derecede etkili bulunmuştur. ${ }^{43,48}$ Opioidler şiddetli ağrıların kontrolünde oldukça etkilidir ancak, yan etkileri nedeniyle kullanımlarında dikkatli olunmalıdır. ${ }^{57}$

Ayrıca topikal olarak $0.025 \%$ 'lik kapsaisin 4 haftalık kullanımı ve \%5 lik EMLA (lokal anesteziklerin ötektik karışımı) kullanımı ağııın azalmasında faydalı bulunmuştur. Kapsaisin periferdeki $C$ liflerinden salınan $P$ maddesi üzerine etki ederek beyin sapı'ndan üst seviyelere iletiyi önleyerek analjezik etkisini gösterir. ${ }^{58}$

Atipik diş ağrısında önerilen tedavi algoritması Tablo 2 ' de gösterilmiştir. ${ }^{16}$

Tablo 2. Atipik diş ağrısı tedavi algoritmas ${ }^{16}$

\begin{tabular}{|c|c|}
\hline $\begin{array}{l}\text { Atipik diş ağrısı } \\
\text { Hasta eğitimi ve bilgilendirilmesi } \\
\text { Topikal Anestezi } \\
\text { (Kapsaisin ve/ya da Lidokain) } \\
\text { Tri siklik Antidepresan } \\
\text { ya da } \\
\text { Seratonin noradrenalin geri alınım inhibitörü } \\
\text { Gabapentin ya da Pregabalin } \\
\text { Tramadol ya da Oksikodon }\end{array}$ & $\begin{array}{c}\text { İnvaziv ted avilerden } \\
\text { kaçınma } \\
+ \\
\text { Gerekli ise } \\
\text { psikolojik konsültasyon }\end{array}$ \\
\hline
\end{tabular}

\section{SONUÇ}

Dişhekimleri atipik diş ağrısı bulunan hastaların ilk ziyaret edeceği hekimler arasındadır. Bu nedenle bu konuda dişhekiminin bilgi sahibi olması hastayı uzun süren ve sonuç vermeyen bir serüvenden kurtaracaktır. Dişhekimi diş tedavisi sonrası klinik ve radyolojik patoloji bulunmamasına rağmen devam eden ağrı ile karşılaşırsa mutlaka atipik diş ağrısını ayırıcı tanıda düşünmelidir. Patofizyolojik mekanizma her vakada farklı olabileceğinden ve etiyolojisi tam olarak bilinemediğinden tedavisinde multidisipliner yaklaşım şarttır.

\section{KAYNAKLAR}

1. Woda A, Pionchon P. A unified concept of idiopathic orofacial pain: clinical features. J Orofac Pain 1999;13:172- 84.

2. MarbachJJ. Orofacial phantom pain: theory and phenomenology. J AmDent Assoc 1996;127:221-9.

3. McElin TW, Horton DT. Atypical facial pain: a statistical consideration of 65 cases. Ann Intern Med 1947;27:749-53.

4. Melis M, Lobo SL, Ceneviz C, Zawawi K, Al-Badawi E, Maloney G, and other. Atypical odontalgia: a review of the literature. Headache 2003; 43:106074. 42.

5. Ohrbach R, List $T$, Goulet JP, Svensson P. Recommendations from the International Consensus Workshop: con- vergence on an orofacial pain taxonomy. J Oral Rehabil 2010;37, 807-12.

6. Headache Classification Subcommittee of the International Headache Society.The International Classification of Headache Disorders, 2nd edn. Cephalalgia 2004;24, 9-160.

7. Israel $H A$, Ward JD, Horrell $B$, Scrivani SJ. Oral and maxillofacial surgery in patients with chronic orofacial pain. J Oral Maxillofac Surg 2003;61:6627.

8. Brooke RI. Atypical odontalgia. A report of twentytwo cases. Oral Surg Oral Med Oral Pathol 1980;49:196-9.

9. Brooke RI, Schnurr RF. Atypical odontalgia. its aetiology and prognosis. N Y State Dent J 1993;59:46-9.

10. Schnurr RF, Brooke RI. Atypical odontalgia. update and comment on long-term follow-up. Oral Surg Oral Med Oral Pathol 1992;73:445-8.

11. Graff-Radford SB, Solberg WK. Is atypical odontalgia a psychological problem? Oral Surg Oral Med Oral Pathol 1993;75:579-82. 
12. Lesse S. Atypical facial pain syndromes of psychogenic origin; complications of their misdiagnosis. J Nerv Ment Dis 1956;124:346-351.

13. Lascelles RG. Atypical facial pain and depression. $\mathrm{Br}$ J Psychiatr 1966;112:651-9.

14. Gatchel RJ, Peng YB, Peters ML, Fuchs PN, Turk DC. The biopsychosocial approach to chronic pain: scientific advances and future directions. Psychological Bulletin 2007;133: 581-624.

15. Brooke RI, Merskey H. Is atypical odontalgia a psychological problem? Oral Surg Oral Med Oral Pathol 1994;77:2-3.

16. Baad-Hansen L. Atypical odontalgia pathophysiology and clinical management. J Oral Rehabil 2008;35:1-11.

17. Rees RT, Harris M. Atypical odontalgia. Br J Oral Surg 1979;16:212-8.

18. Woda A, Tubert-Jeannin S, Bouhassira D, Attal N, Fleiter B, Goulet JP, Gremeau-Richard C, Navez $M L$, Picard P, Pionchon P, Albuisson E. Towards a new taxonomy of idiopathic orofacial pain. Pain 2005;116:396-406.

19. List T, Leijon G, Helkimo M, Oster A, Dworkin SF, Svensson P. Clinical findings and psychosocial factors in patients with atypical odontalgia: a casecontrol study. J Orofac Pain 2007;21:89-98.

20. Tu"rp JC. Die atypische Odontalgie - ein wenig bekannter Phantomschmerz. Schmerz 2001;15:5964.

21. Matwychuk MJ. Diagnostic challenges of neuropathic tooth pain. J Can Dent Assoc 2004 Sep;70:542-6.

22. Hu JW, Woda A, Sessle BJ. Effects of pre-emptive local anesthesia on tooth pulp deafferentationinduced neuroplastic changes in cat trigeminal brainstem neurons. Arch Oral Biol 1999; 44:28793.

23. Chen $R$, Cohen LG, Hallett M. Nervous system reorganization following injury. Neuroscience 2002; 111:761-73.

24. Hu JW, Sharav Y, Sessle BJ. Effects of one- or twostage deafferenta- tion of mandibular and maxillary tooth pulps on the functional proper- ties of trigeminal brainstem neurons. Brain Res 1990; 516:271-9.
25. Bosch-Aranda ML1， Vázquez-Delgado $E$ ， GayEscoda C. Atypical odontalgia: a systematic review following the evidence-based principles of dentistry. Cranio 2011;29:219-26.

26. Campbell RL, Parks KW, Dodds RN. Chronic facial pain associated with endodontic therapy. Oral Surg Oral Med Oral Pathol 1990;69:287-90.

27. Marbach JJ, Hulbrock J, Hohn C, Segal AG. Incidence of phantom tooth pain: an atypical facial neuralgia. Oral Surg Oral Med Oral Pathol 1982;53:190-3.

28. Marbach JJ. Phantom tooth pain. J Endod 1978;4:362-72.

29. Jacobs R1, Wu CH, Goossens K, De Laat A, Van Loven $\mathrm{K}$, Antonis $\mathrm{Y}$, Lambrechts $\mathrm{P}$, van Steenberghe D.A case-control study on the psychophysical and psychological characteristics of the phantom tooth phenomenon. Clin Oral Investig 2002;6:58-64.

30. Klausner JJ. Epidemiology of chronic facial pain: diagnostic useful- ness in patient care. J Am Dent Assoc 1994;125:1604-11.

31. Graff-Radford SB, Solberg WK. Atypical odontalgia. J Craniomandib Disord 1992;6:260-5.

32. Abiko Y, Matsuoka H, Chiba I, Toyofuku A. Current evidence on atypical odontalgia: diagnosis and clinical management. Int J Dent 2012;2012:518548.

33. The International Classification of Headache Disorders, 3rd edition (beta version). Headache Classification Committee of the International Headache Society (IHS). Cephalalgia ;2013: 33: 629-808.

34. Reik L Jr. Atypical odontalgia: a localized form of atypical facial pain. Headache. 1984;24:222-224.

35. Pertes RA, Bailey DR, Milone AS. Atypical odontalgia-a nondental toothache. J N J Dent Assoc $1995 ; 66: 29-33$.

36. Okeson JP. Neuropathic pains. In: Okeson JP, ed. Bell's Orofacial Pains. 5th ed. Chicago, Ill: Quintessence; 1995:403-55.

37. Biron CR. Atypical odontalgia is often dismissed as 'vivid imagination' during diagnosis. RDH. 1996;16:40-4. 
38. Gross SG. Atypical odontalgia: a cause for dental failure. J Conn State Dent Assoc. 1991;67:36-7.

39. Bates RE Jr, StewartCM. Atypical odontalgia: phantom tooth pain. Oral Surg Oral Med Oral Pathol 1991;72:479-83.

40. Saper JR, Silberstein S, Gordon CD, Hamel RL, Swidan S. Facial pain and the neuralgias. In: Saper JR, Silberstein S, Gordon CD, Hamel RL, Swidan S, eds. Handbook of Headache Management. A Practi- cal Guide to Diagnosis andTreatment of Head, Neck, and Facial Pain. 2nd ed. Baltimore, Md: Lippincott Williams\&Wilkins;1999:249-70.

41. Nicolodi M, Sicuteri F. Phantom tooth diagnosis and an anamnestic focus on headache. N Y State Dent J 1993;59:35-7.

42. Sicuteri F, Nicolodi M, Fusco BM, Orlando S. Idiopathic headache as a possible risk factor for phantom tooth pain. Headache 1991;31:577-81.

43. Marbach JJ. Phantom tooth pain: differential diagnosis and treatment. N Y State Dent J 1993;59:28-33.

44. Merskey $\mathrm{H}$, Bogduk N. Classification of Chronic Pain: Descriptions of Chronic Pain Syndromes and Definitions of Pain Terms. 2nd ed. Seattle, Wash: IASP Press; 1994.

45. Okeson JP. Differential diagnosis and management. Considerations of neuralgias, nerve trunk pain, and deafferentation pain. In: Okeson JP, ed. Orofacial Pain: Guidelines for Assessment, Diagnosis, and Management. Chicago, Ill: Quintessence; 1996:73-88.

46. Graff-Radford SB, Ketelaer MC, Gratt BM, Solberg WK.Thermographic assessment of neuropathic facial pain. J Orofac Pain 1995;9:138-46.

47. Ram S, Teruel A, Kumar SK, Clark G. Clinical characteristics and diagnosis of atypical odontalgia: implications for dentists.J Am Dent Assoc 2009;140:223-8.

48. Marbach J], Raphael KG.Phantom tooth pain: a new look at an old dilemma Pain Med 2000;1:6877.

49. Travell JG, Simons DG. Apropos of all muscles. Chapter 3. In: Travell JG, Simons DG, eds. Myofascial Pain and Dysfunction.TheTrigger Point Manual. The Upper Extremities. Baltimore, Md: Williams \& Wilkins; 1983:45-102.

50. Mitchell RG. Pre-trigeminal neuralgia. $\mathrm{Br}$ Dent J 1980;149:167-70.
51. Marbach JJ. Phantom tooth pain: deafferentiation pain. Pa Dent J (Harrisb) 1984;51:32-33.

52. Kreisberg MK. Atypical odontalgia: differential diagnosis and treatment. J Am Dent Assoc 1982;104:852-4.

53. Battrum DE, Gutmann JL. Phantom tooth pain: a diagnosis of exclusion. Int Endod J 1996;29:1904.

54. Marbach JJ. Is phantom tooth pain a deafferentation (neuropathic) syndrome? Part I: Evidence derived from pathophysiology and treatment. Oral SurgOral Med Oral Pathol 1993;75:95-105.

55. Kaspo GA. Atypical odontalgia in the dental office. J Mich Dent Assoc 1995;77:34-6.

56. Lilly JP, Law AS. Atypical odontalgia misdiagnosed as odontogenic pain: a case report and discussion of treatment. J Endod 1997;23:337-9.

57. Tekel N.Postoperatif ağrıların kontrolünde analjeziklerin rolü. Atatürk Üniv. Diş.Hek. Fak. Derg 2007; 17:39-45

58. Vickers ER, Cousins MJ, Walker S, Chisholm K. Analysis of 50 patients with atypical odontalgia. A preliminary report on pharmacological procedures for diagnosis and treatment. Oral Surg Oral Med Oral Pathol Oral Radiol Endod 1998;85:24-32.

\section{Yazışma Adresi}

Dr. Neslihan Tınastepe, Öğr. Gör.

Yeditepe Üniversitesi

Diş Hekimliği Fakültesi, Protetik Diş Tedavisi Anabilim Dalı, No:238, Bağdat Cd, 34728 Göztepe, İstanbul, TÜRKİYE TIf: 02164565345 e-mail: neslihantinastepe@hotmail.com 